University of Montana

ScholarWorks at University of Montana

Numerical Terradynamic Simulation Group

Publications

Numerical Terradynamic Simulation Group

3-1996

\title{
Sensitivity of a general circulation model to global changes in leaf area index
}

Thomas N. Chase

Roger A. Pielke

T. G. F. Kittel

Ramakrishna R. Nemani

Steven W. Running

University of Montana - Missoula

Follow this and additional works at: https://scholarworks.umt.edu/ntsg_pubs Let us know how access to this document benefits you.

\section{Recommended Citation}

Chase, T. N., R. A. Pielke, T. G. F. Kittel, R. Nemani, and S. W. Running (1996), Sensitivity of a general circulation model to global changes in leaf area index, J. Geophys. Res., 101(D3), 7393-7408, doi:10.1029/95JD02417

This Article is brought to you for free and open access by the Numerical Terradynamic Simulation Group at ScholarWorks at University of Montana. It has been accepted for inclusion in Numerical Terradynamic Simulation Group Publications by an authorized administrator of ScholarWorks at University of Montana. For more information, please contact scholarworks@mso.umt.edu. 


\title{
Sensitivity of a general circulation model to global changes in leaf area index
}

\author{
Thomas N. Chase and Roger A. Pielke \\ Department of Atmospheric Science, Colorado State University, Fort Collins
}

Timothy G. F. Kittel

Climate System Modeling Program, University Corporation for Atmospheric Research, Boulder, Colorado

Ramakrishna Nemani and Steven W. Running

School of Forestry, University of Montana, Missoula

\begin{abstract}
Methods have recently become available for estimating the amount of leaf area at the surface of the Earth using satellite data. Also available are modeled estimates of what global leaf area patterns would look like should the vegetation be in equilibrium with current local climatic and soil conditions. The differences between the actual vegetation distribution and the potential vegetation distribution may reflect the impact of human activity on the Earth's surface. To examine model sensitivity to changes in leaf area index (LAI), global distributions of maximum LAI were used as surface boundary conditions in the National Center for Atmospheric Research community climate model (NCAR CCM2) coupled with the biosphere atmosphere transfer scheme (BATS). Results from 10-year ensemble averages for the months of January and July indicate that the largest effects of the decreased LAI in the actual LAI simulation occur in the northern hemisphere winter at high latitudes despite the fact that direct LAI forcing is negligible in these regions at this time of year. This is possibly a result of LAl forcing in the tropics which has longranging effects in the winter of both hemispheres. An assessment of the Asian monsoon region for the month of July shows decreased latent heat flux from the surface, increased surface temperature, and decreased precipitation with the actual LAI distribution. While the statistical significance of the results has not been unambiguously established in these simulations, we suspect that an effect on modeled general circulation dynamics has occurred due to changes of maximum LAI suggesting that further attention needs to be paid to the accurate designation of vegetation parameters. The incorporation of concomitant changes in albedo, vegetation fractional coverage, and roughness length is suggested for further research.
\end{abstract}

\section{Introduction}

It is generally agreed that the extent and type of vegetation covering the earth has changed dramatically in the past due to natural causes [e.g., Street-Perrott et al., 1990; Overpeck, 1993]. That thousands of years of human activity has had an impact on the surface character of the Earth is also undeniable [Otterman, 1977]. However, the extent and magnitude of these changes and their relation to changing climate is much more uncertain.

While it is obvious that human intervention and changes in past climates have had impacts on vegetation [e.g., Houghton, 1994; Street-Perrott et al., 1990; Gornitz, 1987], there is also observational evidence that vegetation can have an impact on climate [e.g., Pielou, 1991]. Meher-Homji [1991], in a review of the impacts of deforestation on local precipitation, found that surface temperature fluctuates more in nonforested regions as opposed to forested areas. He also found evidence that decreased precipitation accompanies decreased forest cover.

Copyright 1996 by the American Geophysical Union.

Paper number 95JD02417. 0148-0227/96/95JD-02417\$05.00
However, the broader impact of vegetation on the atmosphere is inherently difficult to observe due to the time and space scales involved and the lack of adequate analogs for comparison. This leaves the topic in a state of contention and opens the door for experiments with numerical models.

Modelers of climate have become increasingly aware of the importance of the specification of the lower boundary to model simulations. Reviews of these experiments [e.g., Mintz, 1984; Garratt, 1992; Rowntree, 1988] demonstrate that surface designation in a numerical model can have quite large and signifcant impacts on modeled climate.

In numerical models the complicated physical mechanisms of vegetation and its interaction with the atmosphere must be simplified to a few parameters. Many experiments designed to test the impact of vegetation change on climate have described these impacts simply as a change in surface albedo [e.g., Charney, 1975; Sagan et al.. 1979; Potter et al., 1981; HendersonSellers and Gornitz, 1984] implicitly assuming that the largest impact found in vegetation would be its effect on reflectivity. Similar experiments have been performed to ascertain the effect of a change in roughness length due to deforestation [e.g., Sud and Smith, 1985; Sud et al., 1988].

More complicated land surface models are now common 
with the land surface and vegetation changes described according to a greater number of more interactive parameters in recognition that the role of vegetation is not limited to the effect on albedo or roughness of the surface. Attempts to allow vegetation to interact with the atmosphere, to model the effects of transpiration modulation by the canopy and effects on the surface water balance, mean that a measure of the amount of active biomass in a region must be accounted for. This has led to the inclusion of a widely used variable, leaf area index (LAI), in the description of the planetary surface. Defined as the ratio of leaf area to land surface area in a vertical column, LAI is a representation of the density of vegetation at the surface. The primary role of LAI in these models is in regulating the amount of transpiration from the surface and thereby controlling the partition of surface heat fluxes. The larger the leaf area in the column, the more transpiration that can occur. LAI also regulates light extinction in the canopy so that a larger value implies less light reaching the soil surface. Because stomatal conductance is also a function of light [Denmead and Miller, 1976], LAI directly affects the stomatal conductance of individual leaves as well as the integrated conductance of the canopy.

Studies have been performed in an attempt to unravel the properties of vegetation and combinations of properties which are most important in a given situation. For example, in a recent study of statistical-dynamical models of the Earth's surface, Collins and Avissar [1994], using Fourier amplitude sensitivity testing, found that the distribution of surface heat fluxes could be explained mostly by variations in stomatal conductance and roughness length. LAI was found to be significant to the sensible heat flux only under circumstances where the surface is partially vegetated. Using a stand-alone biosphere model, Henderson-Sellers [1993] found the model to be highly sensitive to roughness length and relatively insensitive to LAI designation.

However, Li and Avissar [1994] found that LAI was the most important variable contributing to errors due to neglecting subgrid scale land surface variability. Zhang [1994] found that a dense vegetation cover effectively made surface heat fluxes independent of ground surface conditions, particularly soil moisture. This was based on a vegetation fraction designation, but presumably high values of LAI should have a similar effect. Bonan et al. [1993], using a fairly complex land surface parameterization, found that subgrid heterogeneity in the LAI field was the primary cause of surface flux calculation errors for both wet and dry soils. A strong nonlinear relationship between LAI designation and these fluxes was also apparent. Also noted in this experiment were that many of the effects of increasing leaf area asymptote relatively quickly. For example, most of the influence of increasing leaf area on light extinction occurs at relatively small values of LAI limiting stomatal conductance. However, the area available for energy exchange and water interception increase linearly with leaf area. Clearly, the role of vegetation density and its proxy, LAI, is complex and somewhat ambiguous in parameterizations of surface processes.

Large-scale vegetation changes, modeled comprehensively, have been shown to have large impacts on modeled climate. In an experiment of global scale, Bonan et al. [1992], using a relatively complex surface parameterization and an interactive ocean, found that completely removing the high latitude, boreal forests had large effects on the simulated climate. These simulations included changes in other parameters besides LAI, such as vegetation fraction, and so included direct radiative forcing due to changes in surface albedo. McGuffie et al. [1995] studied tropical deforestation with a version of the communit climate model coupled with BATSIE and a slab ocean model Because tropical forests were changed to scrub grasslands ir this experiment, albedo and roughness length changes werc included in the description of deforestation. Results from this experiment showed locally decreased precipitation as a resul of tropical deforestation as well as remote effects in middle anc high latitudes. Finally, in a study which advances the complex ity of the description of surface characteristics to include veg etation structure which interacts dynamically with climate Henderson-Sellers and McGuffie [1995] find evidence tha changes in vegetation due to altered climate feed back into tha climate and so must be accounted for.

\section{Experiment Description}

The experiment described below is fundamentally a contin uation of past deforestation and land use change numerica experiments. In this case we used the NCAR CCM2 genera circulation model coupled with the biosphere atmospher. transfer scheme (BATS) land surface parameterization. Wc described a change in vegetation globally solely in terms of annual maximum leaf area index (LAI) to ascertain mode' sensitivity to this parameter. The control simulation used a distribution of observed maximum LAI derived from remotel! sensed data as a bottom boundary condition. A second run used a distribution of LAI representing the potential maximun LAI sustainable at a site. We discuss the derivation of thes LAI distributions in more detail in section 4.

The two cases were run for a total of 12 years with the result: from years 3 to 12 used for 10-year January and July ensemblc averages. The first two years were ignored as spin-up time Though the total soil moisture field had not quite equilibratec by the third year, the differences were small and it was felt tc be more important to have two 10-year samples to compare We present results from 10-year averaged Januarys and July: as well as regional results from southern Asia in July.

\section{Model Description, CCM2 and BATS}

The NCAR CCM2 is a primitive equation general circulation model in which variables are solved for using the spectra method. The spectral truncation is triangular allowing 42 wavenumbers in both horizontal dimensions (T42). This corresponds to a grid increment of approximately $2.8^{\circ}$ longitude by $2.8^{\circ}$ latitude ( 128 by 64 points in the horizontal). There are $1 \varepsilon$ vertical levels in a hybrid sigma coordinate system where sigmi levels are used near the surface and blend into a pressurc coordinate above. The model uses climatological sea surfacr temperature data.

The CCM2 includes a diurnal as well as an annual radiatior cycle [Briegleb, 1992]. Shortwave radiation calculations use a delta Eddington approximation. Clouds interact with radia tion. Clouds can form in all tropospheric levels above the first. and cloud fraction is calculated as a function of relative humidity, vertical motion, static stability, and convective precipitation rate.

The parameterization of the planetary boundary layer (PBL: in CCM2 accounts for dry convection by adjusting for nonlocal transport in the boundary layer [Holtslag and Boville, 1993]. The parameterization calculates the PBL height, diffusion pro- 
files, and turbulent transport. A mass flux moist convective scheme is included in the model [Hack, 1994]. A detailed overview of CCM2 can be found in the work of Hack et al. [1993].

The biosphere atmosphere transfer scheme as coupled to the NCAR CCM2 (BATS1E) [Dickinson et al., 1993] was used in these experiments. BATS is a simple land surface parameterization which includes a single vegetation canopy layer and three soil layers. The BATS parameterization computes heat flux partitioning from vegetation and bare soil surfaces along with water budget values and feeds them into the atmospheric portion of the model.

In BATS the Earth's surface is divided among 18 surface types, and representative values of 18 parameters describing properties of vegetation such as maximum and minimum stomatal resistance, maximum and minimum leaf area index, and soil properties are assigned. BATS divides each grid cell into a vegetated and nonvegetated fraction. Vegetation fraction varies regularly with season as a function of subsurface soil temperature only. There is no provision for the effect of soil water (or lack thereof) on vegetation cover. The fluxes of heat and moisture are proportional to the gradient of temperature and vapor pressure between the surface and the first atmospheric level. Vegetation fraction is reduced in the presence of snow.

The leaf area index (LAI) calculation is simple and seasonally varying. For each vegetation category a maximum and a minimum value of single-sided LAI is assigned. The actual value of LAI used in the model is computed in a manner similar to that for vegetation fraction. The value of LAI varies between the maximum and minimum LAI designated in a grid cell as a function only of the subsurface soil temperature. No provision is made for the effect of soil water availability on the distribution of LAI effectively limiting seasonal vegetation changes in the tropics or variations in regions experiencing anomalous precipitation.

In nature, leaf density is related to other vegetation characteristics. For example, larger values of leaf density correspond generally with decreased albedo and higher values of roughness length. In the BATS parameterization, altering the values of maximum LAI by itself does not affect either surface albedo or roughness length of the vegetation because they are independently specified. However, stomatal resistance is directly affected by the designation of LAI. Stomatal resistance is a function of light in the canopy [e.g., Li and Avissar, 1994] and the extinction of light through the canopy is a function of LAI. Greater extinction values create an increased resistance to transpiration. Canopy air temperature and vegetation temperature are also functions of LAI in the BATS parameterization.

\section{Actual Versus Potential Vegetation and its Representation}

A control simulation was performed using a maximum LAI distribution developed by Nemani et al. [this issue] based on normalized difference vegetation index (NDVI) data retrieved from satellite observations. NDVI is the difference between infrared and visible reflectances normalized by their sum. This index has been used to estimate the amount of photosynthetically active material in the canopy [e.g., Sellers et al., 1985; Goward et al., 1986]. It has been found [e.g., Nemani and Running, 1989] that a relationship exists between NDVI data and leaf area of the canopy. Nemani et al. [this issue] used 7 years of NDVI data to reduce the effects of cloud contamina- tion and annual variability. Separate relationships between NDVI and LAI were used for grasses, needle-leaf trees, and broadleaf trees. This is an estimate of the maximum vegetation density as it actually appears today (Plate 1a). The experiment with this LAI distribution is titled actual LAI or actLAI.

In a second simulation a distribution of maximum LAI entitled potential LAI or potLAI was used as a comparison case. Nemani and Running [1989] presented a technique of using a simple ecosystem model to arrive at equilibrium values of leaf area based on inputs from a climatological atmosphere and soil type. Maximum sustainable transpiration at a site is calculated through an iterative technique where transpiration, soil water holding capacity, and precipitation must come into balance. When this balance is achieved, maximum transpiration is reached. Because total leaf area regulates transpiration, maximum LAI is directly related to this total transpiration. They ran the ecosystem model using climatological information on a $0.5^{\circ}$ latitude/longitude grid to obtain an estimated global distribution of maximum sustainable LAI which represents the potential leaf density a site could support assuming equilibrium with current climate (Plate $1 b)$. This estimate of potential LAI does not account for effects of nutrient limitation and natural disturbances (such as forest fires) on vegetation density. While these assumptions can lead to LAI errors in some environments, this method provides a good first-order estimate of potential LAI distribution under current climate. Nemani et $a l$. [this issue] discuss the derivation of these maximum LAI distributions in more detail.

The difference between actual and potential LAI distributions can be taken as a direct estimate of one aspect of human impact on vegetation. It should be noted that the observation of surface characteristics from satellites is imprecise [e.g., $\mathrm{Ga}$ mon et al., 1995]. Imperfect knowledge of soil type, soil moisture, and vegetation type globally can introduce errors into LAI data sets. Modeled distributions of potential LAI such as used in this study are subject to the assumptions inherent in the model used and data sets obtained by varying methods can yield contradictory results (see, for example, the discussion by Neilson [1993]). Some differences between these data sets could be due to differences in method used in deriving them. One is satellite observed (actual LAI) and the other is calculated (potential LAI) through a water balance model. We look at our experiment as a plausible perturbation in global leaf area in magnitude and distribution designed to test the sensitivity of the model to this parameter.

These maximum LAI distributions were averaged to the CCM2 grid using a five nearest-neighbor aggregation (a $2.5^{\circ}$ square area, Plate 1). Because model values of LAI vary with ground temperature between minimum and maximum values, LAI values were generally not at their maximum values throughout the simulation. Differences between the two distributions varied seasonally and tended toward zero in the winter hemisphere. Maps of the differences between the two distributions averaged over the 10 years for January and July are shown in Plate 2. Global land averages in January showed an average LAI of 1.5 for the potLAI case decreasing about $7 \%$ to 1.4 in the actLAI case. In July, averaged LAI decreased $16 \%$ from 1.9 to 1.6 between the two cases.

While these are fairly small LAI differences when averaged globally, actual differences were concentrated in certain areas. In January, LAI differences were concentrated below $20^{\circ} \mathrm{N}$ with the largest differences in Malaysia, southern Asia, southeastern Africa, and northern South America (Plate 2a). In July, 

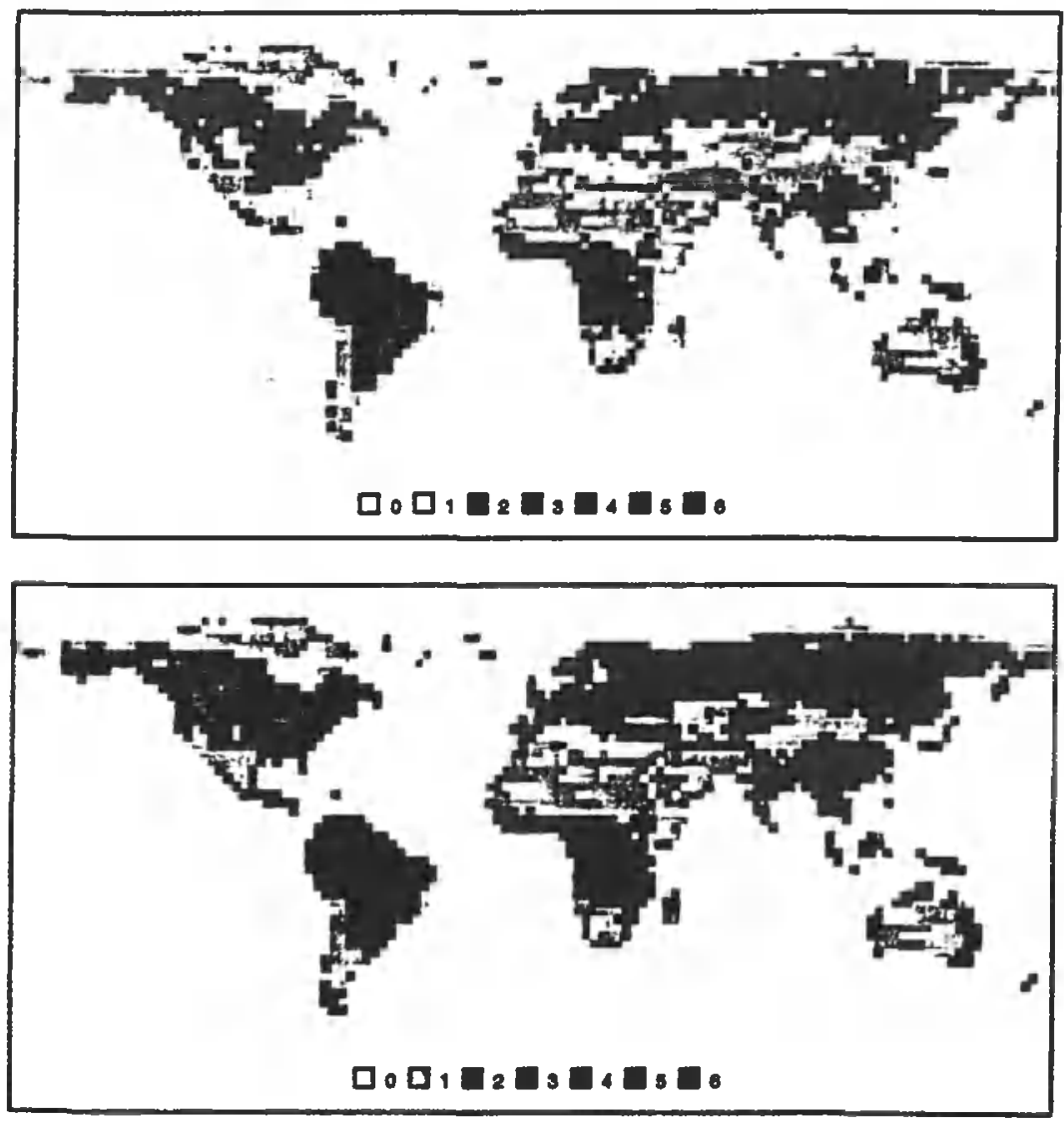

Plate 1. Maps of single-sided leaf area index (LAI), (a) actual LAI, and (b) potential LAl. LAI values run from 0 to 6.
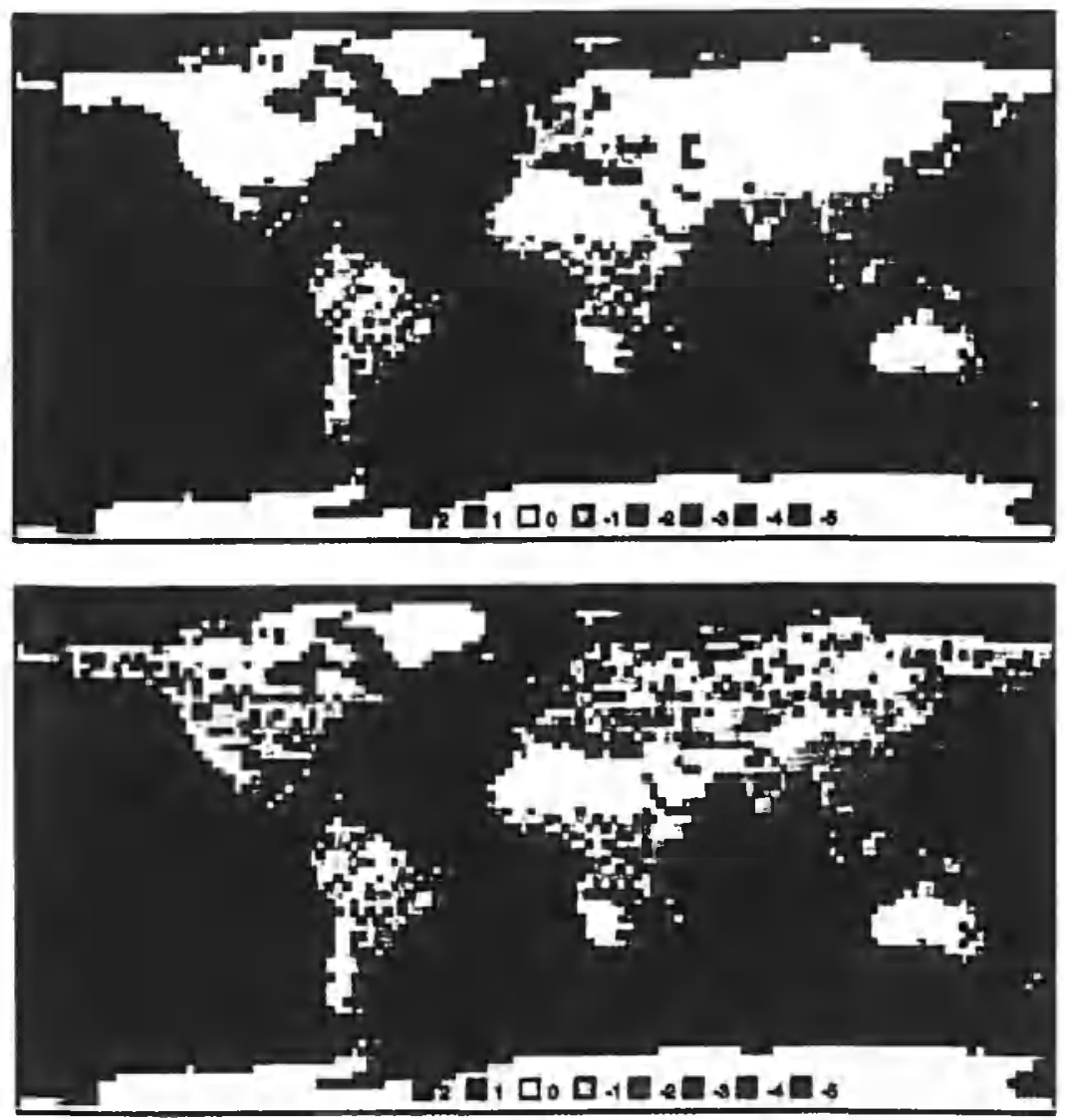

Plate 2. Global 10-year averaged distributions of LAI differences (actLAI-potLAI) for (a) January and (b) July. Negative values indicate a decreased LAI in the actual LAI case. 
differences are noticeable in the eastern United States, western Europe, Japan, Malaysia, southwestern Africa, and northern South America (Figure 2b). Most of these were strongly negative (actLAI-potLAI), indicating a decrease in leaf density in these regions from the potential to actual distributions.

It is expected that the maximum direct forcing due to a change in LAI will be in the summer hemisphere and, in an annually averaged sense, in the tropics. In the tropics, LAI differences between the two simulations remained relatively high and constant throughout the year because of a lack of soil moisture dependency in the LAI calculations. Much of the atmospheric heating in the tropics is associated with landmasses in Africa, South America, and Indonesia [e.g., Ramage, 1968] and is where direct vegetation forcing would be expected to have the largest influence. The magnitude and distribution of heating in this region is a powerful mechanism in generating tropical circulations both in a symmetric sense and for the generation of synoptic-scale waves [e.g., Gill, 1980; Webster, 1983; Meehl, 1993; Hoskins and Karoly, 1981]. Both averaged heating and changes longitudinally in the distribution of tropical heating are associated with large changes in the extratropical latitudes. Rasmussen and Mo [1993] emphasize the regional character of anomalies due to the 1986-1989 El Niño/ Southern Oscillation event and show that the strongest differences in this event were not in alterations in the zonally averaged circulations but in longitudinal deviations from the average which again affected regions well displaced from the tropics. As previously mentioned, McGuffie et al. [1995] found evidence of middle- and high-latitude effects due to tropical deforestation. It may be possible that LAI distribution changes alone have a similar effect.

Because LAI is the only forcing variable in the experiment described in our paper, the partitioning between latent and sensible heat fluxes from the surface due to LAI changes is the primary issue. The question arises as to whether the change in LAI distribution is capable of forcing large enough differences in latent versus sensible heating to fundamentally affect circulations in the summer hemisphere directly, the winter hemisphere indirectly, and the tropics either in magnitude or in distribution.

\section{Global Averages}

The change in LAI distribution from the actLAI case to the potLAI case had little effect in the global average surface climate. In the actual LAI case there was a small planetary surface air temperature warming of less than $0.1 \mathrm{~K}$ in both seasons relative to the potLAl run. Skin temperatures and temperatures $1.5 \mathrm{~m}$ above ground level increased by approximately $0.2 \mathrm{~K}$ over land in July in the actLAI case.

\section{Large-Scale Regional Differences}

The largest differences between actual and potential LAI cases in January averages were in the high northern hemisphere despite the fact that LAI differences were nonexistent in these regions at this time of year. Skin temperatures and air temperatures up to the midtroposphere show large differences above $20^{\circ} \mathrm{N}$. The January $1.5-\mathrm{m}$ air temperatures (Figure 1) increased over all of the continental United States in the actLAI case relative to the potLAI case. with a maximum warming of more than $5 \mathrm{~K}$. A cooling of similar magnitude occurred in most of eastern Canada. A warming of more than $6 \mathrm{~K}$ occurred in the high northern latitudes of Europe and Asia, accompanied by a cooling of several degrees below approximately $55^{\circ} \mathrm{N}$. The southern hemisphere was relatively unaffected in the near-surface temperature field in January; however, smaller magnitude temperature differences between the cases are evident in high southern latitudes in July. Nearsurface air temperature differences followed continental outlines presumably because of the constant sea surface temperatures used as boundary conditions in these simulations.

The pattern of January 500-mbar height differences filtered to include wavenumbers 1-6 only (Figure 2) reproduced the January temperature difference field, indicating that surface temperature differences were due to altered longwave activity between the two cases. The similarity in pattern of $500-\mathrm{mbar}$ height differences and $1.5-\mathrm{m}$ temperature differences also reflects that temperature differences between the two simulations were present vertically through much of the troposphere.

\section{Zonal Averages}

In January the area of peak zonally averaged precipitation (Figure 3 ) shifted northward slightly in the actLAI case relative to the potLAI case. The maximum value in the precipitation peak was also smaller in the actLAI case by nearly $1.0 \mathrm{~mm} / \mathrm{d}$. There was a small decrease in precipitation along the northern hemisphere storm tracks in the actLAI case, while precipitation increased in most of the northern hemisphere subtropics. In July there were few differences between the two cases for zonally averaged total precipitation.

There was a small decrease in the magnitude of the northern hemisphere 200 -mbar jet core in January of nearly $2 \%$, while the southern hemisphere jet increased slightly in magnitude in the actLAI case. The northern hemisphere jet in January also broadened in the actLAI case on the northern side of the jet core. For example, the $20 \mathrm{~m} / \mathrm{s}$ contour at $200 \mathrm{mbar}$ is approximately $1^{\circ}$ latitude farther north in the actLAI case as compared to the potLAI case, while the $25 \mathrm{~m} / \mathrm{s}$ contour is approximately $3^{\circ}$ farther north. Horizontal shear associated with the jet thus decreased in the actLAI case.

The July 200 -mbar jet had a smaller magnitude in both hemispheres in the actLAI case though the changes were small. Velocity contours around the northern hemisphere $200-$ mbar jet remain approximately $2^{\circ}$ farther south in the actLAI case, indicating that the jet contracted from the pole. This is the opposite of the effect seen in January in the northern hemisphere.

The zonally averaged vertical motion field (Figures $4 a-4 c$ ) showed some changes between cases in the January tropics and larger differences at higher latitudes. Peak rising motion at about $5^{\circ} \mathrm{S}$ is less deep in the actLAI case than in the potLAI case, with the $0.03 \mathrm{~Pa} / \mathrm{s}$ contour reaching to approximately 300 mbar in the potLAI case, while in the actLAl case, this contour reached only 400 mbar. The peak in upward motion was also nearly $3^{\circ}$ ( 1 grid interval) farther equatorward in the actLAI case as compared to the potLAI case. This shift in vertical motion was reflected in the northward movement in the precipitation maximum (Figure 2). The maximum vertical velocity near $10^{\circ} \mathrm{S}$ is decreased by about $4 \%$ in the actLAI case. Also of interest is a large (18\%) decrease in maximum lower tropospheric upward motion from $50^{\circ}$ to $60^{\circ} \mathrm{N}$ in the actLAI case. Upward motion was also more shallow in this region reaching 525 mbar in the actLAI case as opposed to 400 mbar in the potLAI case. In July, tropical maximum vertical motion in the 


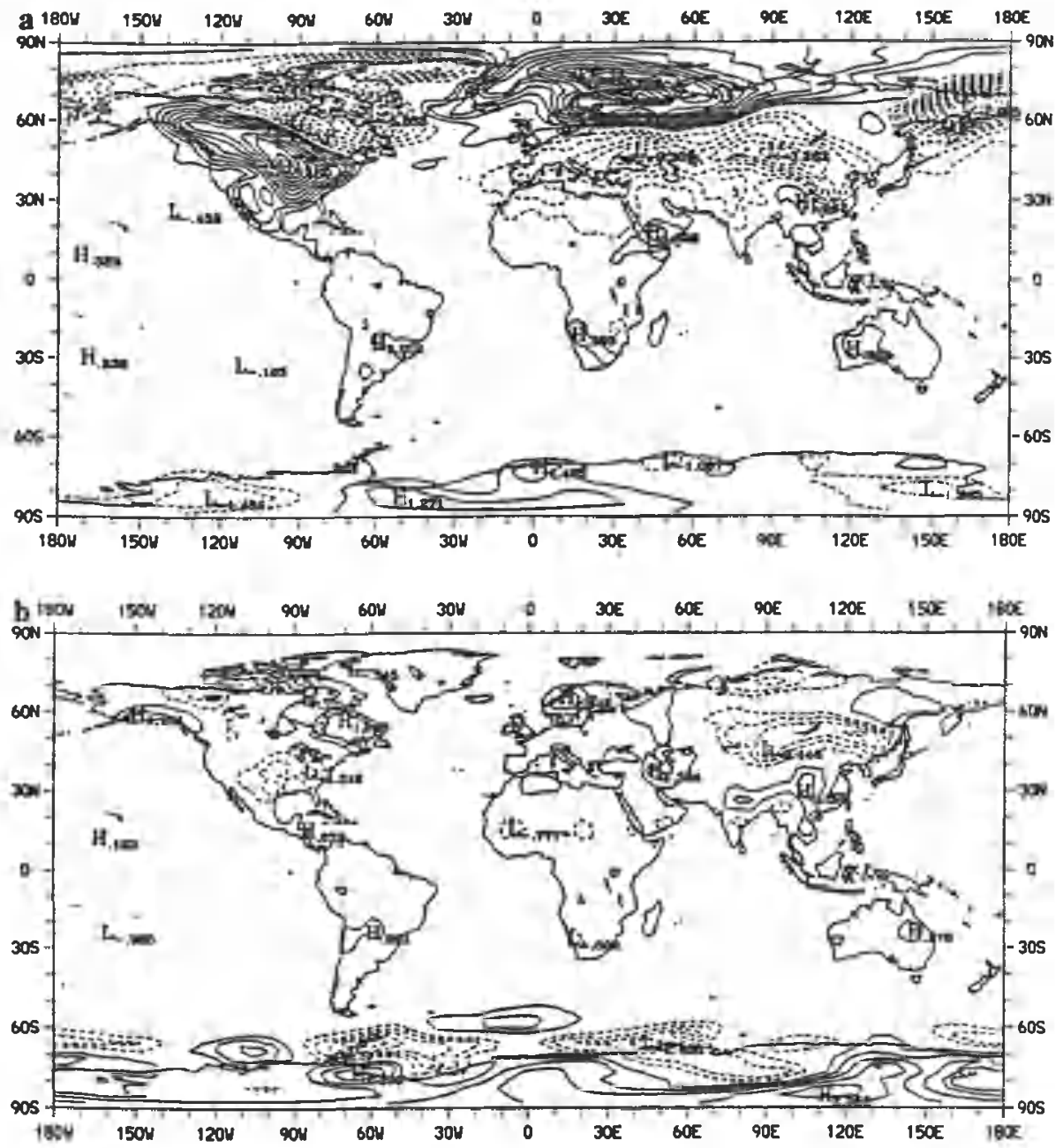

Figure 1. Ten-year averaged differences in 1.5-m air temperature (actLAI-potLAI) in K for (a) January and (b) July. Contours by $0.5 \mathrm{~K}$.

actLAI case was slightly stronger than in the potLAI case but shallower and shifted more equatorward (Figure 4f).

Zonally averaged meridional winds (not shown) showed a slightly decreased magnitude $(6 \%)$ in the actLAI case for January in the Hadley cell upper branch maximum wind. There was also a slight (approximately $2 \%$ ) increase in the maximum magnitude of the Hadley cell inflow from the northern hemisphere. However, maximum mass flux in the winter hemisphere Hadley cell was approximately $2 \%$ smaller in the actLAI case than in the potLAI case. The northern hemisphere Ferrell cell maximum mass flux was larger in the actLAI case than in the potLAI case by approximately $20 \%\left(45 \times 10^{9} \mathrm{~g} / \mathrm{s}\right.$ as compared to $37 \times 10^{9} \mathrm{~g} / \mathrm{s}$ ).

July maximum Hadley cell meridional winds were slightly stronger in the upper branch in the actLAI case as compared to the potLAI case though weaker in the lower branch. Despite this, the southern hemisphere Hadley circulation showed more than a $2 \%$ decrease in maximum mass flux in the actLAI case as compared to the potLAI case indicating that the stronger winds occur over a smaller area. The northern hemisphere Hadley cell mass flux decreased by nearly $15 \%$ in the actLAI case.

\section{Meridional Averages}

To better understand mechanisms responsible for the less vigorous Hadley circulations and zonal jets in both January and
July in the actLAI simulation, surface quantities for each season were averaged over the latitude band which correspondec to the area of mean tropical ascending motion. For Januar. this belt lies approximately from $2^{\circ} \mathrm{N}$ to $22^{\circ} \mathrm{S}$. In July the av eraging area was from $2^{\circ} \mathrm{N}$ to $22^{\circ} \mathrm{N}$.

Table 1 summarizes mean quantities over land in the lat $i$ tude bands corresponding to mean upward motion for botl January and July. There was a slightly larger average decreas in LAI in the actLAI case in January than in July and differ ences in surface fluxes in January were more than double th July values. The actLAI case showed increased sensible hea: flux, decreased latent heat flux, and decreased precipitation ir both seasons as compared to the potLAI case. Skin temperatures in the actLAI case increased in January but not in July Outgoing longwave radiation (OLR) values for the actLAI casi increased on average in January but decreased in July. However. the largest change in total precipitation occurred in July.

Maximum averaged differences in LAI between the tw cases in these latitude bands were 1.8 in July as opposed to 1.5 in January (the maximum value of LAI in the model is 6). In January the largest differences occurred in Africa, followes closely by the Americas, and were smallest in Asia in January Note that in January the averaging domain extends only to $2^{\circ} \mathrm{N}$ so that the main landmasses of Asia are not included in the domain. We use Asia here for convenience in referring to 


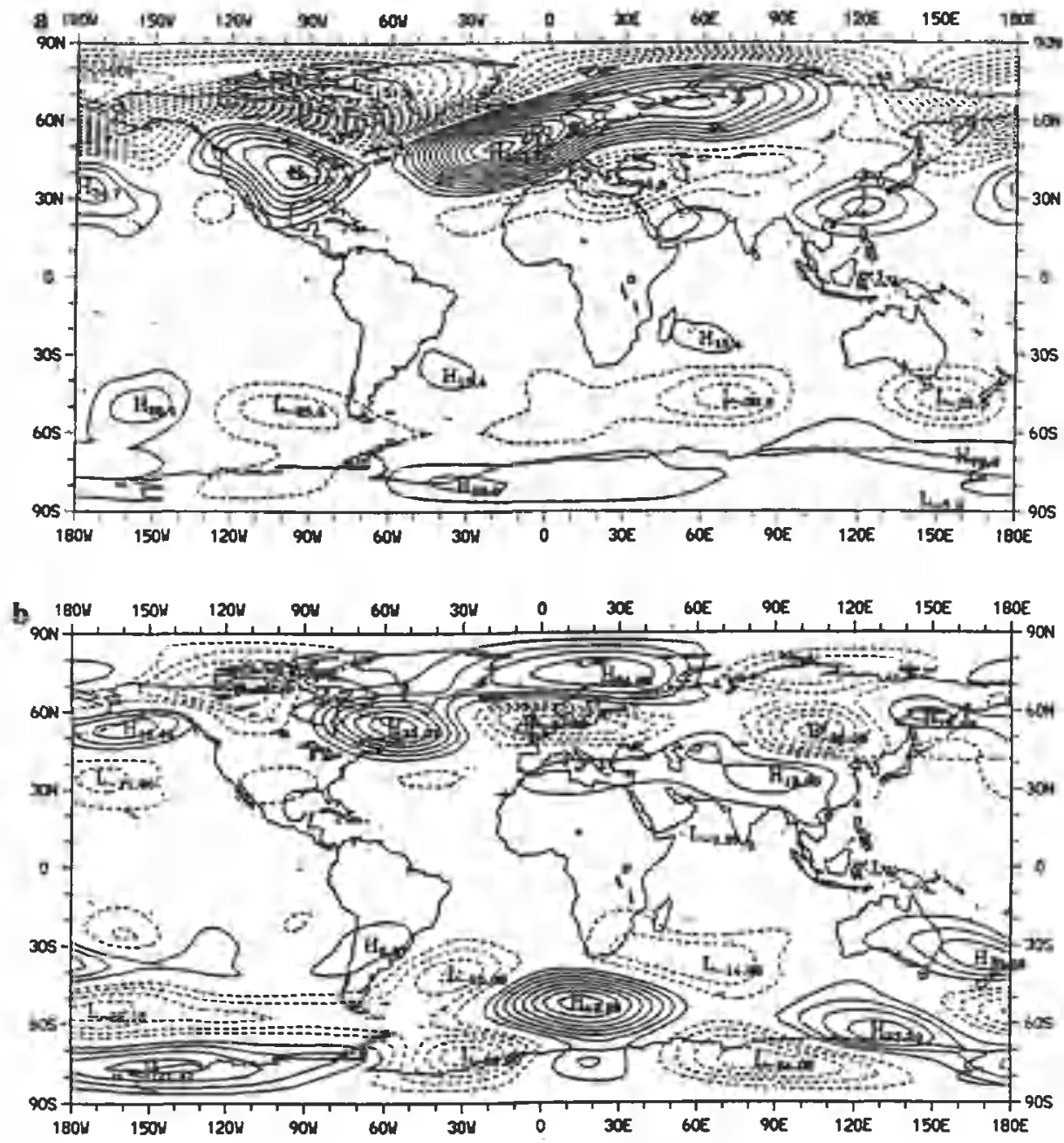

Figure 2. Ten-year averaged differences in 500-mbar heights zonal wavenumbers 1-6 only (act-LAIpotLAI). (a) January, contour $10 \mathrm{~m}$, and (b) July, contour $5 \mathrm{~m}$.

Indonesia and the maritime continent. July LAI differences were largest in Asia and followed by the Americas and were relatively small in magnitude and area in Africa.

In January, difference fields comparing surface latent heat flux from $2^{\circ} \mathrm{N}$ to $22^{\circ} \mathrm{S}$ showed decreased latent heat flux over land in the actLAI case with a maximum decrease of $12 \mathrm{~W} / \mathrm{m}^{2}$ occurring in the Americas. Decreases of about $8-10 \mathrm{~W} / \mathrm{m}^{2}$ covered most of Africa. A sharp increase of approximately 11 $\mathrm{W} / \mathrm{m}^{2}$ occurred in western Asia, while a decrease in latent heat flux of about $4 \mathrm{~W} / \mathrm{m}^{2}$ occurred in eastern Asia. This latter area was a region of small changes in LAI. Differences in sensible heating patterns occurred almost exclusively in regions affected by a change in LAI. Areas of increased sensible heating occurred on nearly all land areas in the averaging domain with a maximum increase of nearly $15 \mathrm{~W} / \mathrm{m}^{2}$ in the Americas for the actLAI case.

An estimate of the vigor of convection in the tropics is outgoing longwave radiation with OLR decreasing with deeper convection. In January, OLR increases in the actLAI case over the Americas reached $12 \mathrm{~W} / \mathrm{m}^{2}$. Off the eastern coast of Africa in the Indian Ocean, increases in the actLAI case were in excess of $20 \mathrm{~W} / \mathrm{m}^{2}$, and over eastern Asia, OLR increased 5 $\mathrm{W} / \mathrm{m}^{2}$. Over the eastern Pacific the Atlantic and Africa OLR decreased in the actLAI case, indicating increased convective activity in these regions.
In July, decreases in mean latent heat flux in the latitudes from $2^{\circ} \mathrm{N}$ to $22^{\circ} \mathrm{N}$ for the actLAI case were largest in Asia which corresponds to the region of largest decrease in LAI. The maximum decrease was nearly $30 \mathrm{~W} / \mathrm{m}^{2}$ for the actLAI case. A decrease of $25 \mathrm{~W} / \mathrm{m}^{2}$ developed in the Americas. For the same case, increases in sensible heating occurred in the Americas and Asia in direct correlation with decreases in latent heat flux. The largest increase was nearly $19 \mathrm{~W} / \mathrm{m}^{2}$ in Asia.

OLR increases of up to $16 \mathrm{~W} / \mathrm{m}^{2}$ occurred over the Americas in the actLAI case in July. Over Africa, OLR decreased in this case to $8 \mathrm{~W} / \mathrm{m}^{2}$. Over Asia and the maritime continent, OLR increased by up to $11 \mathrm{~W} / \mathrm{m}^{2}$. It should be emphasized that the differences described in this section were small in the sense that differences between cases were smaller than the year-toyear variability of the fields in the model.

\section{Horizontal Momentum Fluxes}

Figure 5 displays comparisons of the horizontal momentum fluxes representing deviations from the zonal mean flow averaged vertically from 1000 to 100 mbar. Northward momentum flux associated with stationary waves in January was somewhat larger in magnitude in the actLAI case than for the potLAI case in the northern hemisphere. There was, however, a considerable decrease in southerly momentum transport poleward 

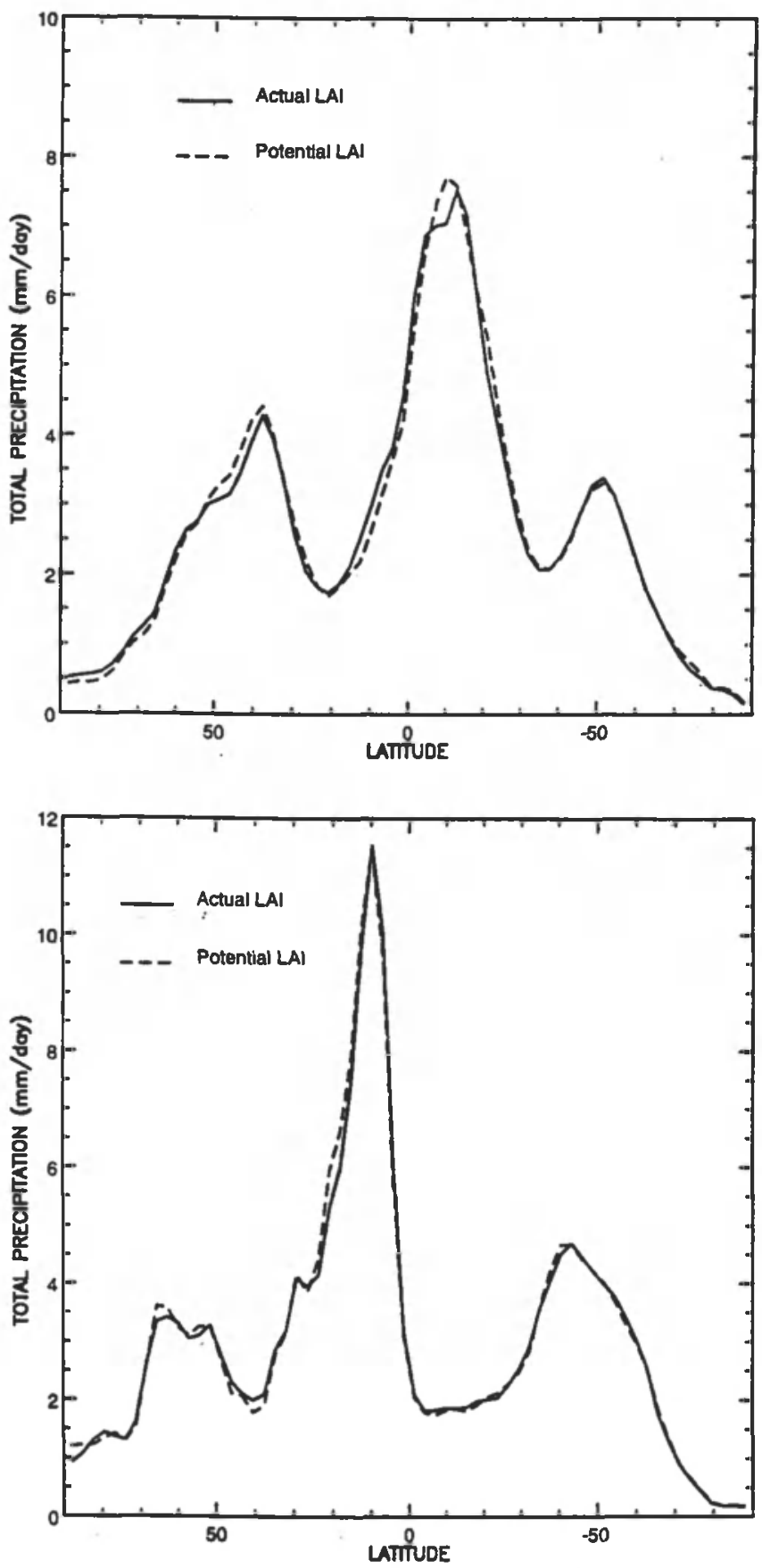

Figure 3. Zonally averaged total precipitation in millimeters per day for (a) January and (b) July. South latitudes are negative.

of $50^{\circ} \mathrm{N}$ in the actLAI case creating a decrease in zonal momentum convergence and shifting the area of convergence farther north.

In July the northern hemisphere standing wave fluxes were similar in the two cases though the actLAI case had slightly smaller magnitude in far northem latitudes. Larger differences in the flux patterns were seen in the southern hemisphere. The actLAI case had larger magnitude zonal momentum fluxes which were conșistẹntly positive in the southern hemisphere poleward of $40^{\circ} \mathrm{S}$, while momentum fluxes for the potLAI case in the southern hemisphere were negative until about $70^{\circ} \mathrm{S}$.

Fluxes representing deviations from the time mean also dis- played interesting differences between the two experiments. Differences between the vertically averaged (1000-100 mbar), zonally averaged transient fluxes are shown in Figure 6. In January, transient eddy fluxes of zonal momentum are larger in magnitude for the actLAI case between $55^{\circ} \mathrm{N}$ and $70^{\circ} \mathrm{N}$. Between $30^{\circ} \mathrm{N}$ and $55^{\circ} \mathrm{N}$, transient transport of zonal momentum was considerably smaller for the actLAI simulation. The decrease in transient flux in this region in the actLAI case was associated with a northern midlatitude decrease in precipitation (Figure 2). Again, there was less convergence of zonal momentum at about $60^{\circ} \mathrm{N}$ for the actLAI case. This decrease in zonal momentum convergence presumably served to decrease the magnitude of the jet, thereby increasing its stability, and so further reduced transport by transient eddies. In July, transient activity was generally smaller in magnitude in the northern midlatitudes for the actLAI case. Transient eddy momentum flux was larger in magnitude for the actLAI case in most of the southern hemisphere.

\section{Interannual Variability}

As an example of the differences in variability between the two simulations, Figure 7 compares the variance of 500-mbar heights for the two experiments. In the regions poleward of the polar front, the variance of the actLAI fields was substantially smaller in both seasons and for both hemispheres. The decrease in variance for the actLAI case was nearly $40 \%$ at the peak in January. In July, the peak variance in the southern hemisphere also shifted equatorward approximately $15^{\circ}$ in the actLAI case.

\section{Asian Monsoon}

A closer look at southern Asia during northern summer is interesting for several reasons. First, this region was subject to relatively large increases in LAI over a large continuous area. Also, these changes were from large values (potLAI) to small values (actLAI). If LAI differences resulted in changed atmospheric conditions, then it should be noticeable here. Second. there is much interest in the influence of the land surface on the strength of the Asian summer monsoon [e.g., Meehl, 1993. 1994; Fennessey et al., 1994].

Ten years of July averages have been used to represent the summer monsoon season. Though this is not ideal, it was felt that this would be somewhat representative of the summer monsoon season as a whole. A summary of regionally averaged differences over land surfaces from $10^{\circ} \mathrm{S}-35^{\circ} \mathrm{N}$ to $65^{\circ}-130^{\circ} \mathrm{E}$ are presented in Table 2 . In this region the actLAI case had more than a $20 \%$ decrease in LAI on average compared to the potLAI case. As a consequence, there was an decrease in latent heat flux from the surface of 133.2 to $126.8 \mathrm{~W} / \mathrm{m}^{2}$. Sensible heat fluxes increased from 47.6 to $53.4 \mathrm{~W} / \mathrm{m}^{2}$. This was followed by a $0.3 \mathrm{~K}$ increase in $1.5-\mathrm{m}$ temperatures for the actLAI case. A $0.5 \mathrm{~K}$ increase in maximum daily temperature occurred in this region, while minimum daily temperature decreased 0.3 $\mathrm{K}$. The increased vegetation increased the diurnal temperature range. $A$ decrease in total precipitation in the actLAI case occurred over land surfaces from 12.5 to $11.8 \mathrm{~mm} / \mathrm{d}$ in this region. July precipitation decreases over land oceurred largely over Nepal and Tibet, southeastern Asia, and the northern Philippines (Figure 8). Increased precipitation occurred over southern India. 

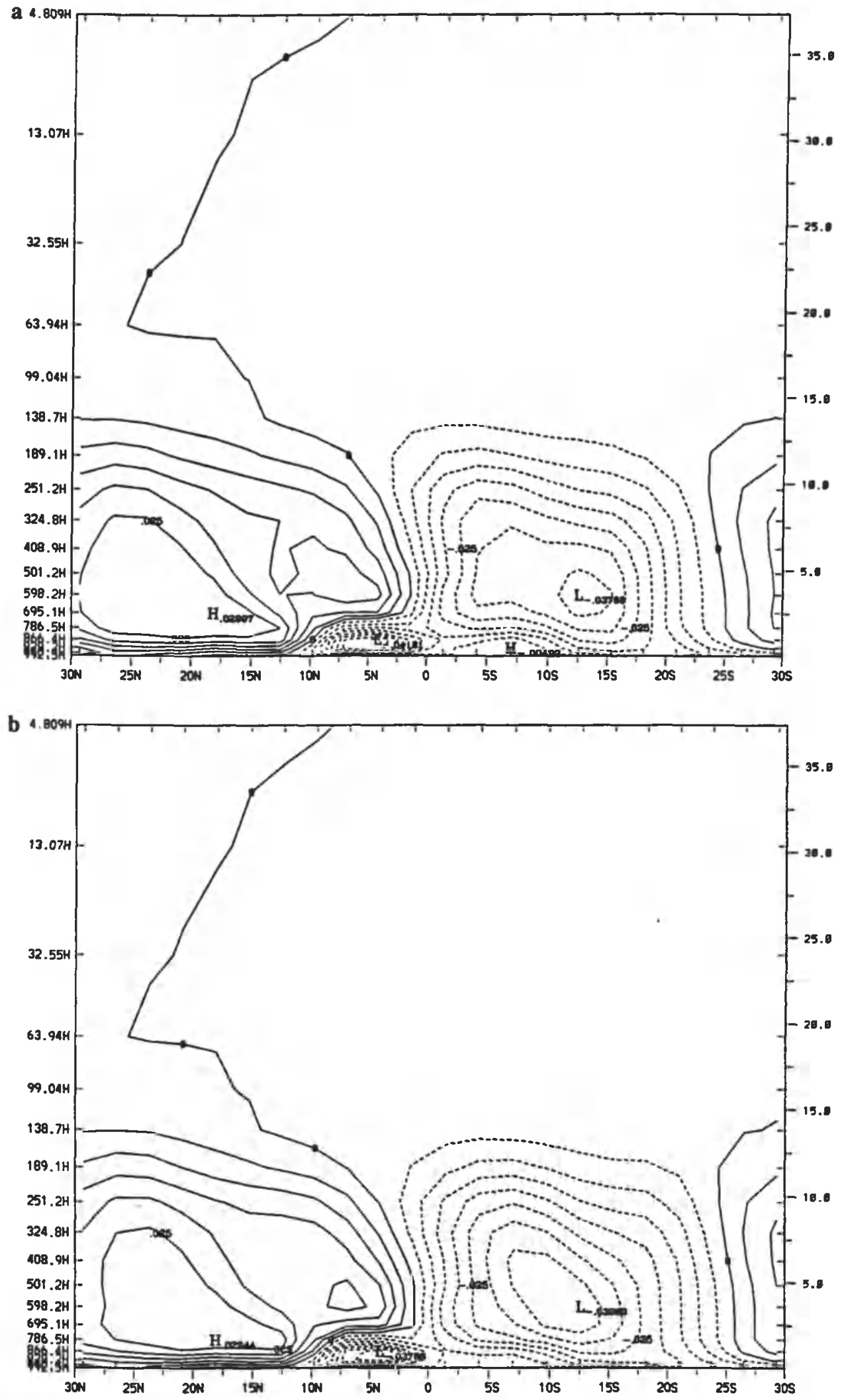

Figure 4. Zonally averaged pressure velocity in millibars per second for the region $30^{\circ} \mathrm{N}-30^{\circ} \mathrm{S}$ for (a) January, actLAI; (b) January, potLAI; (c) January, difference (actLAI-potLAI); (d) July, actLAI; (e) July, potLAI; and (f) July, difference (actLAI-potLAI). Rising motion is indicated with negative contours. 

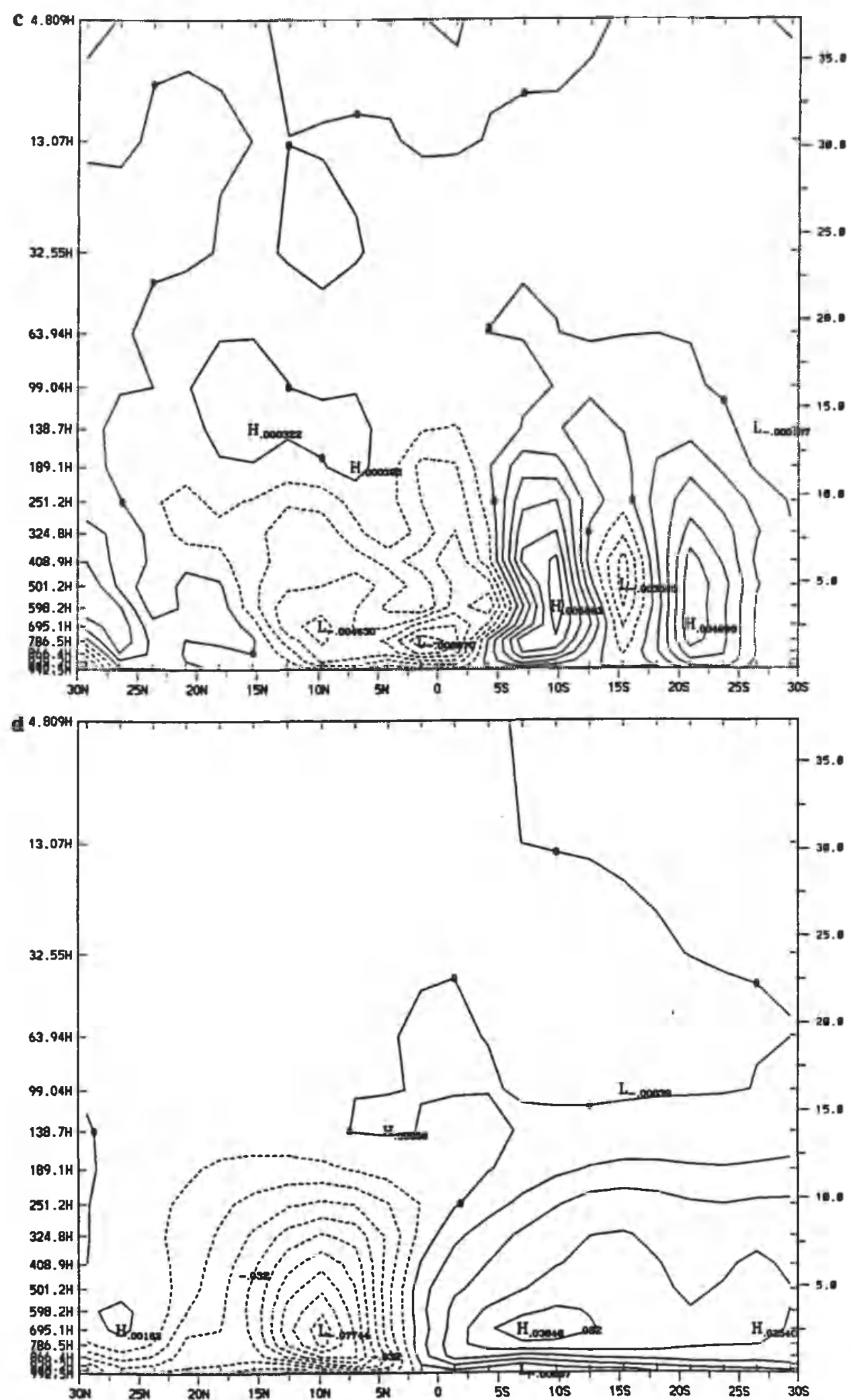

Figure 4. (continued)

\section{Statistical Significance}

The statistical significance of results from this experiment was estimated using the methodology described by Chervin and Schneider [1976] based on the $t$-test statistic. Figure 9 displays contoured values of this statistic at the $80 \%(t=1.33), 90 \%$ (1.73), $95 \%$ (2.10), and $98 \%$ (2.55) significance levels for the 500-mb height field in January and July. The areas along the storm tracks in the northern hemisphere in January clearly showed regions of significant difference between the two experiments. In the zonal average the $t$ statistic was greater than the $80 \%$ significance level for most of the northern hemisphere north of $60^{\circ} \mathrm{N}$. In July the region of highest significance was the 

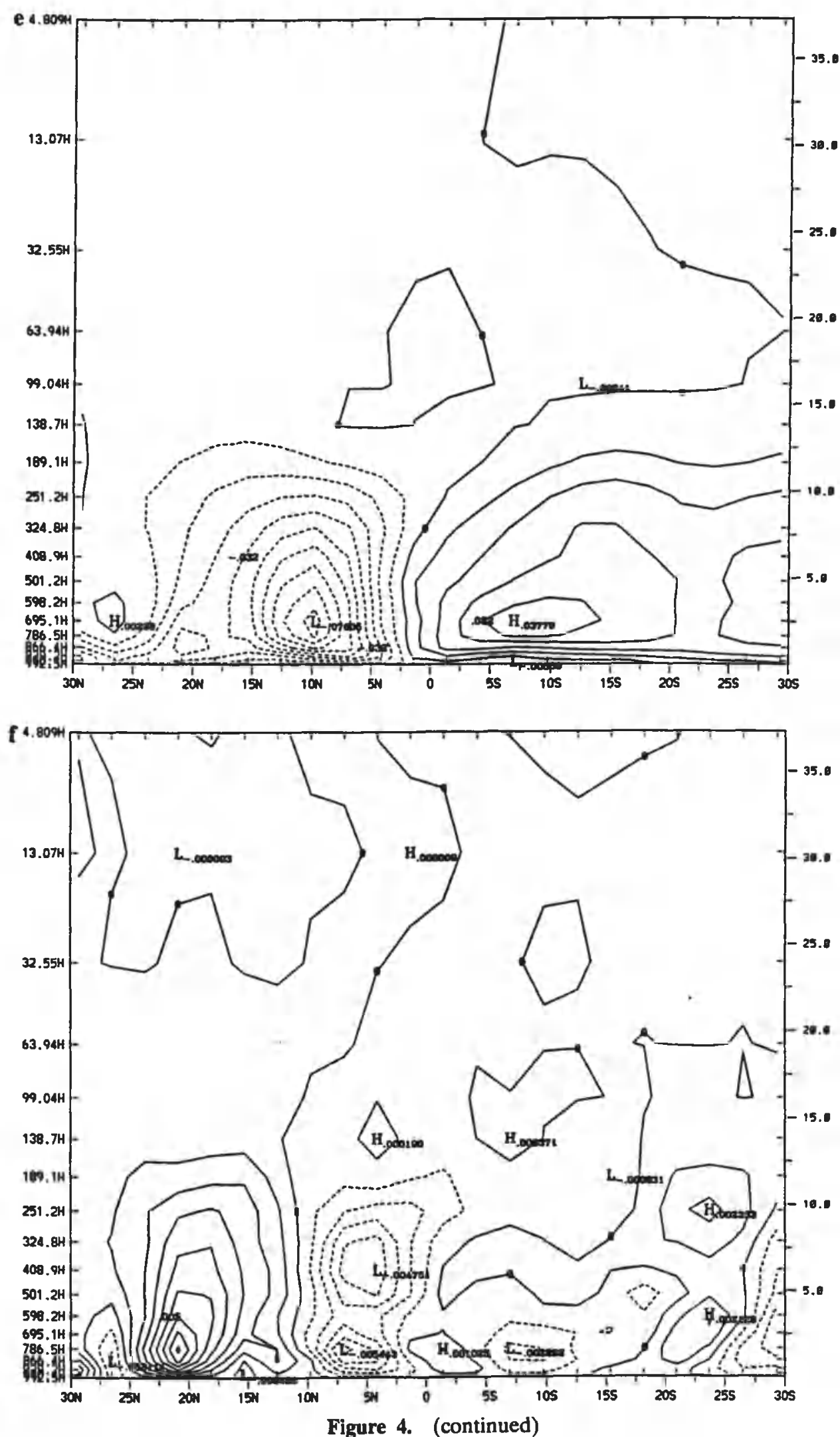

tropics where greater than $90 \%$ significance level was reached from approximately $5^{\circ} \mathrm{N}$ to $10^{\circ} \mathrm{S}$. The zonally averaged planetary circulation shows differences between experiments, but these differences tend to be smaller than model variability. Regions of $80 \%$ or higher significance exist but are isolated so that significant levels are smoothed out in the zonal average and therefore are statistically unreliable.

Because statistical tests are not conclusive, comparisons between the first 5-year and the second 5-year means have been made in order to test the consistency of results in separate 
Table 1. Average Differences Over Land Surfaces (actLAIpotLAI) for Tropical Latitudes Corresponding to Mean Upward Motion

\begin{tabular}{lcl}
\hline \multicolumn{1}{c}{ Variable } & January & July \\
\hline Leaf area index & -0.7 & -0.6 \\
Sensible heat flux, $\mathrm{W} / \mathrm{m}^{2}$ & +2.4 & +1.1 \\
Latent heat flux, $\mathrm{W} / \mathrm{m}^{2}$ & -2.6 & -1.0 \\
Skin temperature, $\mathrm{K}$ & +0.17 & -0.05 \\
Outgoing longwave radiation, $\mathrm{W} / \mathrm{m}^{2}$ & 1.3 & -1.0 \\
Total precipitation, mm/d & -0.09 & -0.34 \\
\hline
\end{tabular}

January $\left(2^{\circ} \mathrm{N}-22^{\circ} \mathrm{S}\right)$ and July $\left(2^{\circ} \mathrm{N}-22^{\circ} \mathrm{N}\right)$.
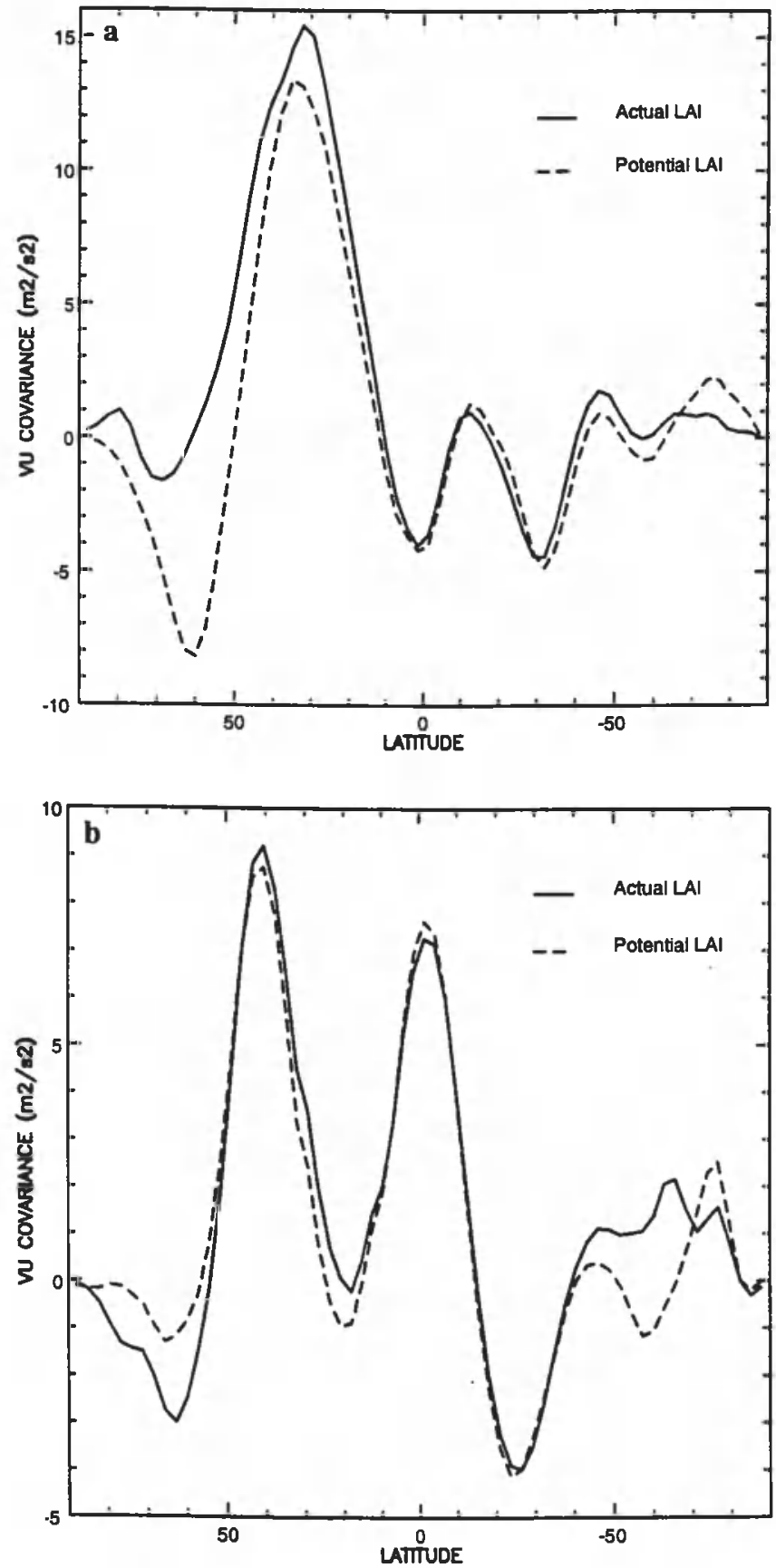

Figure 5. Vertically averaged (1000-100 mbar) standing eddy fluxes for (a) $[\overline{V * U *}]$ January and (b) $[\overline{V * U *}]$ July.
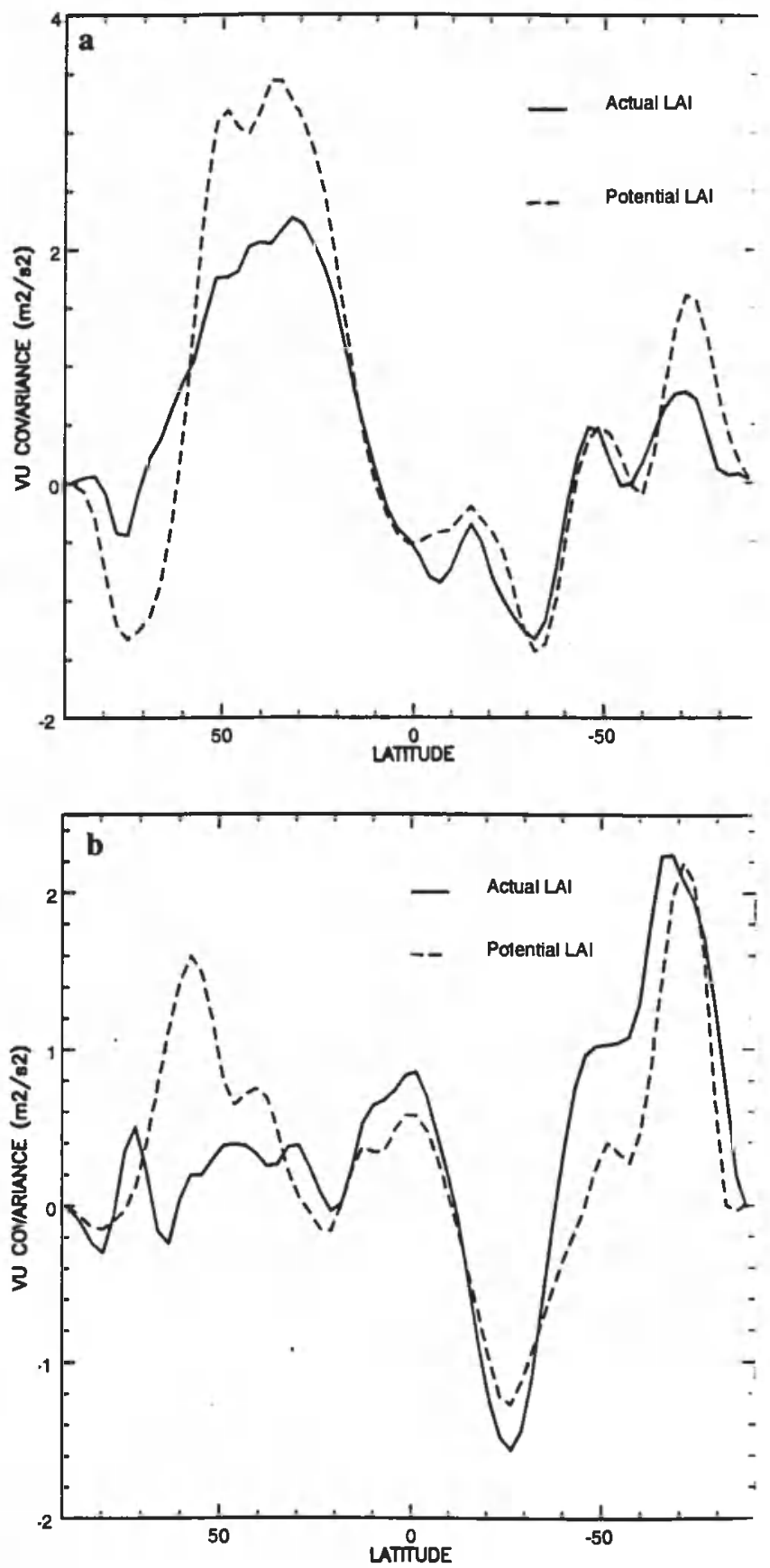

Figure 6. Vertically averaged (1000-100 mbar) transien' eddy fluxes for (a) $\left[\overline{V^{\prime} U^{\prime}}\right]$ January and (b) $\left[\overline{V^{\prime} U^{\prime}}\right]$ July.

subsets. Both 5-year samples show differences along the winte. hemisphere polar front which can be ascribed to altered wavi patterns. Moreover, the differences in pattern are very simila in each 5-year mean, indicating that a constant rather tha random perturbation is responsible. Both 5-year averages show decreased latent heat flux in the tropics, weaker Hadley circu lations, and broader, slower jets in January in the actLAI case Both 5-year averages show decreased variability in the actLA! case and decreased convergence of zonal momentum in January in the northern hemisphere. Results from the Asian mon soon region are also consistent between the two 5-year sample. with an overall decrease in precipitation over land, a warmin: of the surface, decreased latent heat fiux, and increased sen sible heat flux in the actLAI case. 

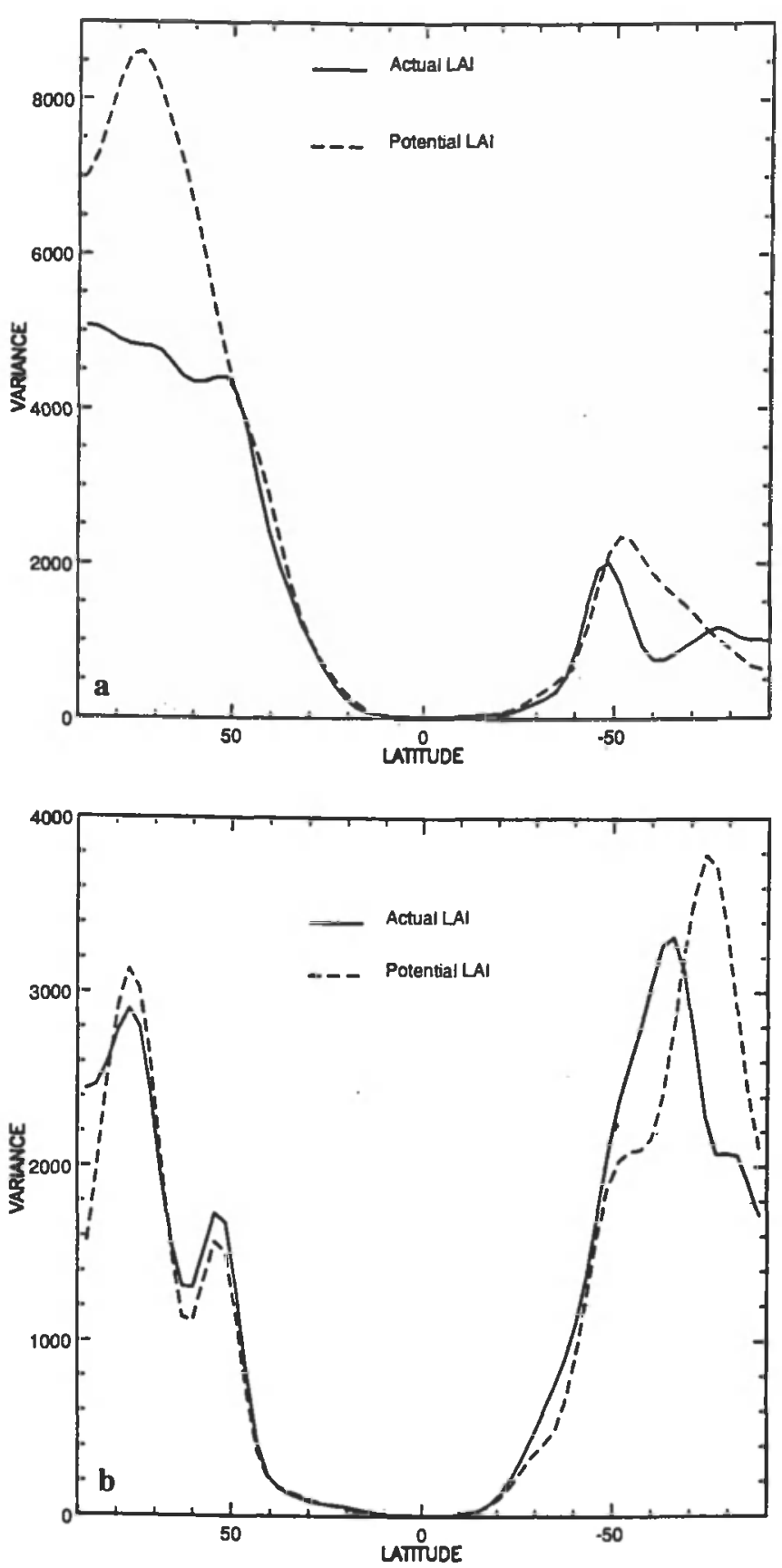

Figure 7. Zonally averaged variance of 500-mbar heights in square meters for (a) January and (b) July.

\section{Discussion and Conclusions}

An experiment designed to test the sensitivity of numerically modeled climate to a change in maximum leaf area index using a plausible perturbation was performed. This change is the difference between a global distribution of maximum LAI observed from satellite and an estimate of the distribution of maximum LAI modeled to be in equilibrium with current observed climate.

Globally averaged fields in these experiments showed few differences. The changing distribution and magnitude of LAI would be expected to initially alter only the partitioning between latent and sensible heat fluxes from the surface. While differences in this partitioning may possibly have large consequences regionally due to altered circulation patterns, it is unlikely that changes would be seen in globally averaged and time-averaged fields. An exception to this would occur if cloud cover was altered or changes in soil moisture were induced by the LAI change. Both these factors affect global albedo and therefore the planetary energy budget [e.g., Ramanathan et al., 1989; Otterman, 1977]. Because differences in both total cloudiness and soil moisture were negligible in the global average, there is no reason to expect that these will play anything but a small role in this experiment in terms of global-mean effects. However, large-scale features in the atmosphere were affected by the change from the potential LAI distribution to the actual LAI distribution in the simulations. This was seen in higher latitudes in winter in both hemispheres as well as in the tropics.

Statistically significant differences at high northern latitudes in January seen in 1.5-m temperatures or the 500-mbar height's are attributed to changes in the structure of waves along the polar front. It is inferred that these differences were generated by changes in atmospheric heating patterns in the tropics initiated by decreased average latent heat flux from the surface in the actual LAI simulation and from changes in the meridional distribution of heating. These changes in tropical heating" patterns appear to have altered the meridional structure in the 200-mbar jet and so the generátion of waves. This was evident in January in the region of the Americas where the jet shows a $14 \%$ decrease in peak magnitude. While regional differences in latent heat flux were larger in the July tropics, there was less of an effect at higher latitudes in the southern hemisphere. This would seem to be due to the greater role eddies have in the northern hemisphere because of the larger percentage of land surface.

Differences between the actual LAI simulation and the potential LAI simulation were also found in the tropics at the latitudes of maximum upward motion. While scattered areas of greater than $90 \%$ statistical significance occurred in this region, the significance of the results throughout the tropics and higher latitudes is not fully established. However, these differences were often consistent in comparisons of two 5-year samples. This suggests that a longer integration would differentiate a similar signal as described here from model noise. There was an decrease of surface latent heat flux and increased sensible heat flux over land in both January and July due to the decreased LAI in the actLAI case. The decreased latent heat flux surpassed the increased sensible heat flux in absolute value in both seasons, so that the surface was supplying less total energy

Table 2. Ten-Year July Land Averages $\left(65^{\circ}-130^{\circ} \mathrm{E}\right.$, $10^{\circ} \mathrm{S}-35^{\circ} \mathrm{N}$ )

\begin{tabular}{|c|c|c|c|}
\hline Variable & July & & $\%$ Change \\
\hline Leaf area index & -1.38 & & $-20.8 \%$ \\
\hline Total sọil moisture, mm & -0.12 & & $\cdots$ \\
\hline Skin temperature, $\mathbf{K}$ & +0.40 & & $\cdots$ \\
\hline Maximum $1.5-\mathrm{m}$ temperature, $\mathrm{K}$ & +0.54 & & $\cdots$ \\
\hline Minimum 1.5 -m temperature, $\mathrm{K}$ & -0.34 & & $\cdots$ \\
\hline Average $1.5-\mathrm{m}$ temperature, $\mathrm{K}$ & +0.29 & & .. \\
\hline Sensible heat flux, $\mathrm{W} / \mathrm{m}^{2}$ & +5.8 & & $+12.1 \%$ \\
\hline Latent heat flux, $\mathrm{W} / \mathrm{m}^{2}$ & -6.4 & & $-4.8 \%$ \\
\hline Total clouds (frac) & +0.02 & & $+2.4 \%$ \\
\hline Total precipitation, $\mathrm{mm} / \mathrm{d}$ & -0.66 & & $-5.2 \%$ \\
\hline Runoff, $\mathrm{mm} / \mathrm{d}$ & -0.46 & .. & $-6.3 \%$ \\
\hline Shortwave at surface, $\mathrm{W} / \mathrm{m}^{2}$ & +3.43 & & $\cdots$ \\
\hline
\end{tabular}

Summary of differences between control and perturbed (actLAIpotLAI) and the percentage change. 


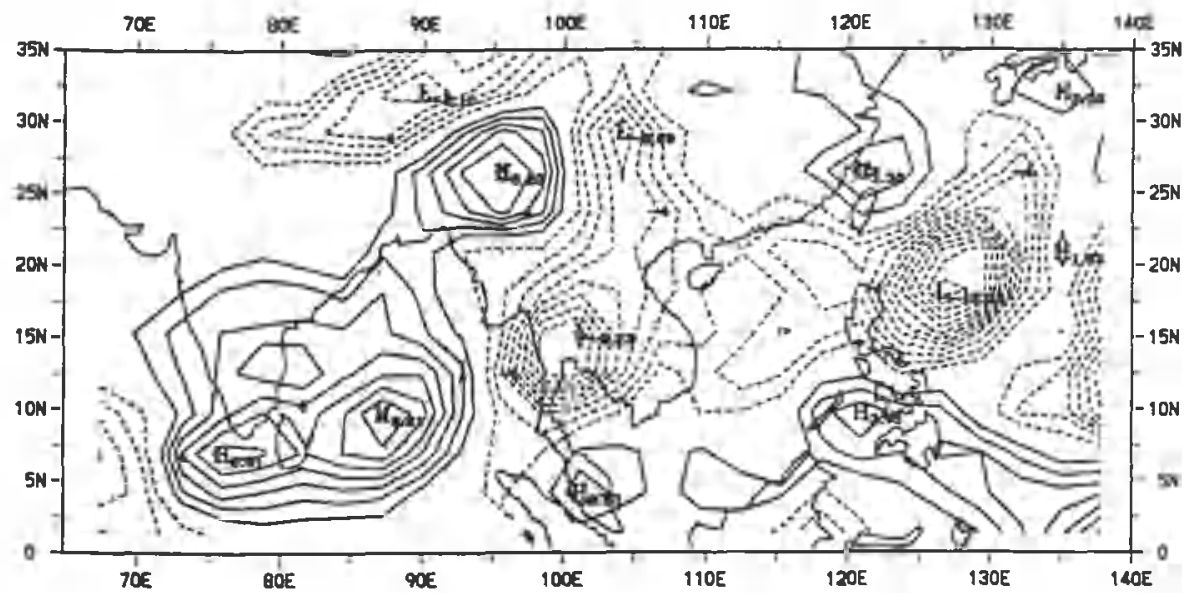

Figure 8. July total precipitation differences (actLAI-potLAI) $65^{\circ}-130^{\circ} \mathrm{E}, 10^{\circ} \mathrm{S}-35^{\circ} \mathrm{N}$ in millimeters per day:

to the atmosphere on average. A small decrease in total precipitation was seen in the tropical latitudes of interest in both seasons. Decreased precipitation and increased OLR in January indicates weaker tropical convection in this season. This may explain the small decrease in magnitude of the Hadley cell mass flux and in the magnitude of the 200 -mbar norther hemisphere jet in January. Despite the decreased precipitatior in July in the tropical latitude belt of ascending motion, OLR decreases in July indicate an increase in convective activity. This contradiction emphasizes the weakness of the signal duc

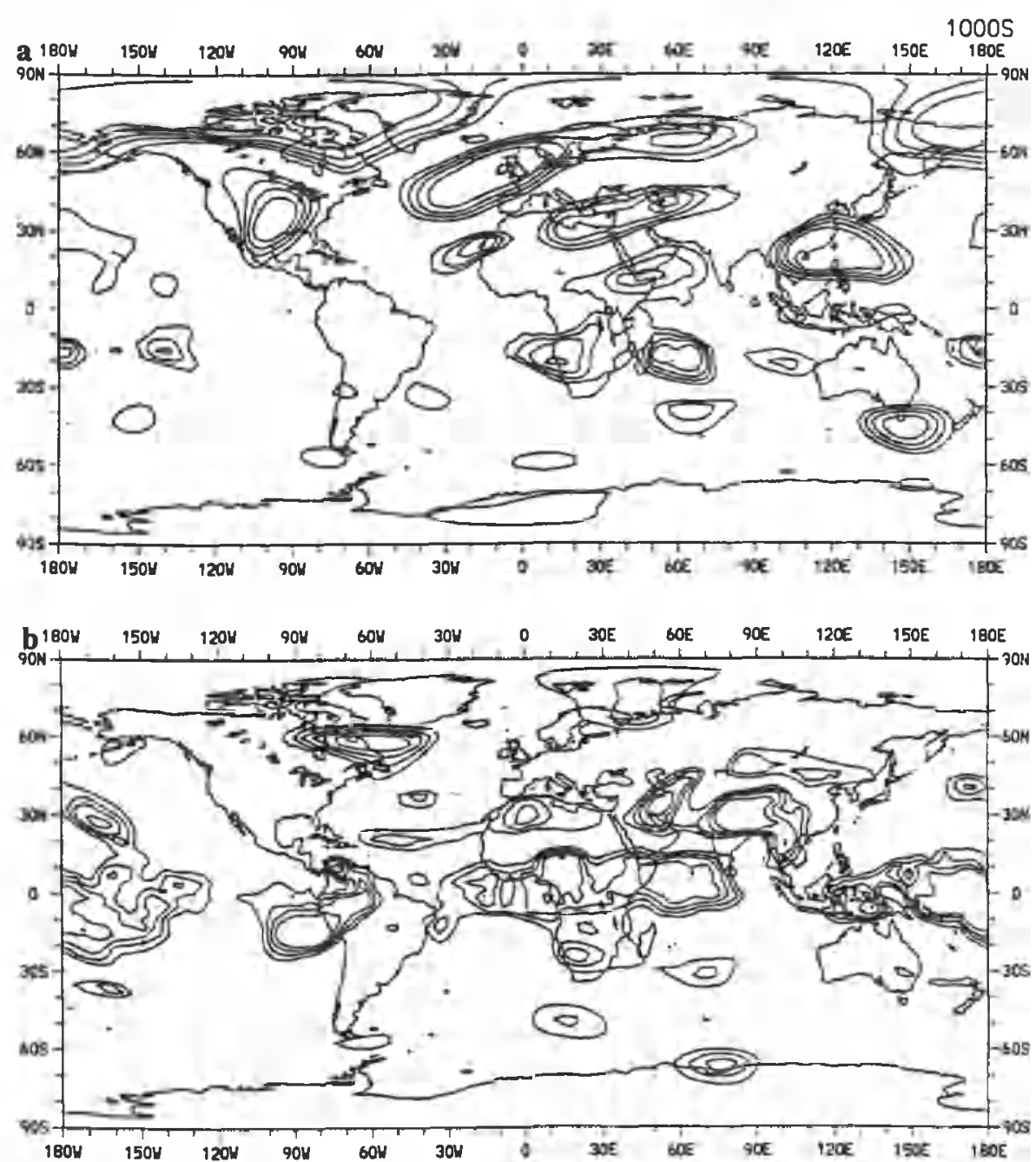

Figure 9. The $t$ statistic: (a) January 500-mbar heights and (b) July 500-mbar heights. Contours are the 80, 90,95 , and $98 \%$ significance levels. 
to altered LAI relative to other processes at work. The mean meridional circulation and the winter hemisphere jet were also slightly weaker in this season.

The region of the Asian monsoon in July displayed a similar response to the decrease in LAI in the actual LAI case as the tropics as a whole. There was decreased latent heat flux over land, increased sensible heat flux, and an decrease in total precipitation.

The most striking differences between the two cases described here occurred in the realm of interannual variability and eddy fluxes. There was decreased variability in the actual LAI simulation along and poleward of the winter hemisphere polar fronts which again point to alterations in the generation of waves due to influences from the tropics.

Finally, it should be emphasized that this was a minimal change scenario designed to test the sensitivity of the model to perturbation in LAI. Interactions among biophysical changes associated with altered vegetation structure are needed to consider the effect of vegetation as a whole on climate: Future work should include time-varying roughness length, vegetation albedos, vegetation fraction, and other parameters used to describe the vegetation cover which are compatible with the LAI distribution. Further, because neither vegetation fraction nor minimum LAI were altered along with the maximum LAI, this experiment may be considered to have evaluated minimal forcing arising from changes in LAI. Presumably, the decreased density of vegetation seen in the actual LAI distribution in most areas also covered smaller fractional areas of the surface, and so effects due to LAI changes would be proportionally larger. Nonetheless, the designation of LAI as part of the bottom boundary condition in this model appears to have had an effect on the climate generated, suggesting that further attention to the accurate specification of vegetation density is necessary.

Acknowledgments. Support for this study was provided by the National Park Service and National Biological Service under contract CA 1268-2-9004. COLR-R92-0204. NSF grant ATM-9306754, and UCAR's Climate System Modeling Program which is supported by the NSF. We would like to thank NCAR for providing computer time and access to CCM2. NCAR is partially supported by the National Science Foundation. We thank Jill Baron. Dave Randall. Jeff Copeland, Bryan Critchfield, Dallas McDonald. and two anonymous reviewers for their comments and assistance in this study.

\section{References}

Bonan, G. B., D. Pollard, and S. L. Thompson. Effects of boreal forest vegetation on global climate. Nature. 359.716, 1992.

Bonan, G. B., D. Pollard, and S. L. Thompson. Influence of sub-grid scale heterogeneity in leaf area index. stomatal resistance. and soil moisture on grid-scale land-atmosphere interactions, J. Clim., 6 , 1882-1897, 1993.

Briegleb, B. P., Delta Eddington approximation for solar radiation in the NCAR community climate model. J. Geophys. Res., 97, 7603$7612,1992$.

Charney, J. G., Drought in the Sahara: A biogeophysical feedback mechanism, Science, 187, 434-435, 1975.

Chervin, R. M., and S. H. Schneider. On determining the statistical significance of climate experiments with general circulation models, J. Atmos. Sci., 33, 405-412, 1976.

Collins, D. C., and R. Avissar. An evaluation with the Fourier amplitude sensitivity test of which land-surface parameters are of greatest importance in atmospheric modeling. J. Clim.. 7, 681-703, 1994.

Denmead, O. T., and B. D. Miller. Field studies of the conductance of wheat leaves and transpiration. Agron. J.. 68. 307-311, 1976.

Dickinson, R. E., A. Henderson-Sellers. and P. J. Kennedy, Biosphere- atmosphere transfer scheme (BATS) version le as coupled to the NCAR community climate model, NCAR Tech. Rep., NCARITN$387+S T R, 72$ pp., Natl. Cent. for Atmos. Res., Boulder; Colo., 1993.

Fennessey, M. J., et al., The simulated Indian monsoon: A GCM sensitivity studv, J. Clim., 7, 33-43, 1994.

Gamon, J. A., G. C. Bield, M. L. Goulden, K. I. Griffin, A. E. Hartley, G. Joel. J. Penuelas, and R. Valentini, Relationships between NDVI, canopy structure, and photosynthesis in three California vegetation types, EcoL Appl, 5, 28-41, 1995.

Garratt, J. R., Sensitivity of climate simulations to land-surface and atmospheric boundary-layer treatments-A review, J. Clim., 6, 419449, 1992.

Gill. A. E., Some simple solutions for heat-induced tropical circulations, Q. J. R. Meteorol. Soc., 106, 447-462, 1980.

Gornitz, V., Climatic consequences of anthropogenic vegetation changes, in Climate History, Periodicity and Predictability, edited by M. R. Rampino, J. E. Sanders, W. S. Newman, and L. K. Konigsson, pp. 47-70, Van Nostrand Reinhold, New York, 1987.

Goward, S. N., C. J. Tucker, and D. G. Dye, North American vegetation patterns observed with the NOAA-7 Advanced Very High Resolution Radiometer, Vegetatio, 64, 3-14, 1986.

Hack, J. J., Parameterizations of moist convection in the National Center for Atmospheric Research community climate model (CCM2), J. Geophys. Res., 99, 5551-5568, 1994.

Hack. J., B. Boville, B. Briegleb, J. Kiehl, P. Rasch, and D. Williamson, Description of the NCAR Community Climate Model (CCM2), NCAR Tech. Note, NCAR/TN-382+STR, 108 pp., Natl. Cent. for Atmos. Res., Boulder, Colo., 1993.

Henderson-Sellers. A., A factorial assessment of the sensitivity of the BATS land-surface parameterization scheme, J. Clim., 6, 227-247, 1993.

Henderson-Sellers, A., and V. Gornitz, Possible climatic impacts of land cover transformations with particular emphasis on tropical deforestation. Clim. Change, 6, 231-257, 1984.

Henderson-Sellers, A., and K. McGuffie, Global climate models and 'dynamic' vegetation. Global Change Biol., 1, 63-75, 1995.

Holtslag, A. A. M., and B. A. Boville, Local versus nonlocal boundary layer diffusion in a global climate model, J. Clim., 6, 1825-1841, 1993.

Hoskins. B. J., and D. J. Karoly, The steady linear response of a spherical atmosphere to thermal and orographic forcing, J. Atmos. Sci., 38, 1179-1196. 1981.

Houghton. R. A., The worldwide extent of land-use change, Bioscience, 44. 305-313, 1994.

Li. B.. and R. Avissar, The impact of spatial variability of land-surface characteristics on land surface heat fluxes, J. Clim., 7, 527-537, 1994.

McGuffie, K.. A. Henderson-Sellers, H. Zhang, T. B. Durbidge, and A. J. Pitman. Global climate sensitivity to tropical deforestation, Global Planet. Change, 10, 97-128, 1995.

Meehl. G. A., Influence of the land surface in the Asian summer monsoon: External conditions versus internal feedbacks, J. Clim., 7, 1033-1049, 1993.

Meehl, G. A.. Coupled land-ocean-atmosphere processes and South Asian monsoon variability, Science, 266, 263-267, 1994.

Meher-Homji, V. M., Probable impact of deforestation on hydrological processes, Clim. Change, 19, 163-173, 1991.

Mintz, Y.. The sensitivity of numerically simulated climates to landsurface boundary conditions, in The Global Climate, edited by J. Houghton, pp. 79-105, 1984.

Neilson. R.. Vegetation redistribution: A possible source of $\mathrm{CO}_{2}$ during climate change, Water Air Soil Pollut., 70, 659-673, 1993.

Nemani, R. R., and S. W. Running, Testing a theoretical climate-soilleaf area hydrologic equilibrium of forests using a satellite data and ecosystem simulation, Agric. For. Meteorol., 44, 245-260, 1989.

Nemani. R., S. W. Running, R. A. Pielke, and T. N. Chase, Global vegetation cover changes from coarse resolution satellite data, $J$. Geophys. Res., this issue.

Otterman. J., Anthropogenic impact on the albedos of earth, Clim. Change, 1, 137-155, 1977.

Overpeck. J. T., The role and response of continental vegetation in the global climate system, in Global Changes in the Perspective of the Past. edited by J. A. Eddy and H. Oeschger, John Wiley, New York, 1993.

Pielou. E. C.. After the Ice Age: The Return of Life to Glaciated North America. 366 pp., University of Chicago Press. Chicago, Ill., 1991. 
Potter, G. L., H. W. Ellsaesser, M. C. MacCracken, and J. S. Ellis, Albedo change by man, Nature, 291, 47-49, 1981.

Ramage, C. S., Role of a tropical "maritime continent" in the atmospheric circulation, Mon. Weather Rev., 96. 365-370, 1968.

Ramanathan, V., R. D. Cess, E. F. Harrison, P. Minnis, B. R. Barkstrom, E. Ahmad, and D. Hartmann. Cloud-radiative forcing and climate: Results from the earth radiation budget experiment, Science, 6, 57-63, 1989.

Rasmussen, E. M., and K. Mo, Linkages between 200 -mb tropical and extratropical circulation anomalies during the 1986-1989 ENSO cycle, J. Clim., 6, 595-616, 1993.

Rowntree, P. R., Review of GCMs as a basis for predicting the effects of vegetation change on climate, in Forests, Climate and HydrologyRegional Impacts, edited by E. R. C. Reynolds and F. B. Thompson, $162 \mathrm{pp}$., United Nations University, New York, 1988.

Sagan, C., O. B. Toon, and J. B. Pollack, Anthropogenic climate changes and the Earth's climate, Science, 206, 1363-1368, 1979.

Sellers, P. J., Canopy reflectance, photosynthesis, and transpiration, Int. J. Remote Sens., 6, 1335-1372, 1985.

Street-Perrott, F. A., J. F. B. Mitchell, and D. S. Marchand, Milankovich and albedo forcing of the tropical monsoons: A comparison of geological evidence and numerical simulations for 9000 y BP, Trans R. Soc. Edin. Earth Sci., 8I, 407-427, 1990.

Sud, Y. C., and W. E. Smith, The influence of surface roughness of deserts on the July circulation, Boundary Layer Meteorol., 33, 45-49 1985.

Sud, Y. C.. J. Shukla, and Y. Mintz, Influence of land surface rough ness on atmospheric circulation and precipitation: A sensitivity stud with a general circulation model, J. Appl. Meteorol., 27, 1036-1054 1988.

Webster, P. J., Large scale structure of the tropical atmosphere, it Large Scale Dynamical Processes in the Atmosphere, edited by B. J Hoskins and R. P. Pearce, Academic, San Diego, Calif., 1983.

Zhang, T.. Sensitivity properties of a biosphere model based on BAT: and a statistical-dynamical climate model, J. Clim., 7, 890-913, 1994

T. N. Chase and R. A. Pielke, Department of Atmospheric Sciencc Colorado State University, Fort Collins, CO 80523.

T. G. F. Kittel, Climate System Modeling Program, University Cor poration for Atmospheric Research, P.O. Box 3000, Boulder, CC 80307.

R. Nemani, School of Forestry, University of Montana, Missouli MT 59812.

(Received February 21, 1995; revised June 23, 1995; accepted July 24, 1995.) 